\title{
Could the Construction of Sustainable Development Pilot Zones Improve the Urban Environment Efficiency in China?
}

\author{
Junxia Ma, ${ }^{1,2}$ Zilong Zhang $\mathbb{D D}^{1,2,3}$ Chenyu Lu ${ }^{\mathbb{D}},{ }^{4}$ and Bing Xue ${ }^{5}$ \\ ${ }^{1}$ Key Laboratory of Western China's Environmental Systems (Ministry of Education), \\ College of Earth and Environmental Sciences, Lanzhou University, Lanzhou 730000, China \\ ${ }^{2}$ Institute for Circular Economy in Western China, Lanzhou University, Lanzhou 730000, China \\ ${ }^{3}$ Institute of Green Development for the Yellow River Drainage Basin, Lanzhou University, Lanzhou 730000, China \\ ${ }^{4}$ College of Geography and Environmental Science, Northwest Normal University, Lanzhou 730070, China \\ ${ }^{5}$ Institute for Advanced Sustainability Studies (IASS), Potsdam 14467, Germany
}

Correspondence should be addressed to Zilong Zhang; zhangzl@lzu.edu.cn

Received 26 December 2019; Accepted 10 February 2020; Published 12 March 2020

Academic Editor: Maria Alessandra Ragusa

Copyright (c) 2020 Junxia Ma et al. This is an open access article distributed under the Creative Commons Attribution License, which permits unrestricted use, distribution, and reproduction in any medium, provided the original work is properly cited.

As the forerunner and policy test field of the sustainable development, the sustainable development pilot zones are an important strategy for China to explore the mechanism and model of the coordinated development of human and land in different regional units. However, the impact of sustainable development pilot zones, especially on the improvement of environmental efficiency, needs to be assessed. In this paper, 187 prefecture-level cities in China were taken as samples (22 sustainable development pilot zones and 165 nonpilot ones). Firstly, the environmental efficiency of 187 prefecture-level cities between 2006 and 2016 was measured by data envelopment analysis (DEA). Then, the effect of construction of sustainable development pilot zones on environmental efficiency was assessed using the difference-in-difference (DID) model. The assessment results were further verified by propensity score matching with difference-in-difference (PSM-DID). In addition, the impact mechanism of construction of the sustainable development pilot zones on the environmental efficiency was discussed. Results show that the environmental efficiency of sustainable development pilot zones is $27.7 \sim 31.7 \%$ greater than that of nonsustainable one, which is mainly attributed to the environmental regulation and industrial structure adjustment.

\section{Introduction}

Since the reform and opening up, China has entered a period of rapid development. Urbanization has become a huge engine of economic and social development in China following industrialization [1]. With the extensive development model of "large-scale mining, large-scale consumption, large-scale waste," the contradiction between the high-speed urbanization and environmental protection has become increasingly prominent, and urban environmental issues have become the focus of the society [2]. In addition, the problems of the lag in social development, destruction of biodiversity, and the deterioration of the ecological environment emerged [3-5]. Since the 1960s, in the face of prominent environmental problems and ecological crises, the international community has actively explored the coordinated development among the economy, society, and the environment [6]. On the First International Conference on Human Environment in 1972, researchers called on governments and peoples around the world to work together, improve the environment, and benefit all human being and future generations [7]. In 1980, the International Union for Conservation of Nature first proposed the concept of sustainable development, and American researcher Lester Brown proposed the basic path of sustainable development. In 1987, the World Commission on Environment and Development officially proposed the definition of sustainable development [8]. Then, the sustainable development has become a hot topic worldwide. Agenda 21 of the United Nations, the Global Action of Millennium Goals, and the 
2030 Sustainable Development Goals (SDGs 2030) all focus on promoting global sustainable development [9].

Since the concept of sustainable development was put forward, the indicator system, sustainability evaluation, path design, and policy effects of sustainable development have been global hot spots $[7,10,11]$. Driven by global researches and policy practices of sustainable development, countries around the world have attempted to improve environmental, economic, and social sustainability by implementing a series of policies including poverty alleviation, pollution control, resource conservation, and ecological restoration. Developed regions and countries, such as the European Union, promote the environmentally friendly development using advanced science and technology as well as flexible policy regulation, thus achieving the goal of regional sustainable development [12]. In addition, the European Union has included the sustainable development as the primary and basic policy in the "Amsterdam Treaty," guiding the overall socioeconomic development of the European Union [13, 14]. The United States responded positively and established the "Presidential Council on Sustainable Development" to review and introduce a report on the sustainable development strategy of the United States [15]. The developing regions and countries, mainly in Africa and South America, aim to alleviate the absolute poverty and avoid "poverty pollution." They have adopted various models and implemented series of policies to solve the problems of public health, education, and national livelihoods $[16,17]$. Developed countries, such as Europe and the United States, actively provide various types of technical and scientific assistance for the developing countries to promote the global sustainable development.

China has always adopted "sustainable development" as one of the basic state policies [2]. In response to the Rio Conference, China established the 21 Century Agenda Management Center in 1994 and took the lead in publishing Agenda 21 [18]. In 1996, it was clearly stated that "implementing sustainable development and pushing on the comprehensive development of the society" is a national strategy. Subsequently, at the 15th and 16th National Congress of the Chinese Communist Party, it was pointed out that the sustainable development is the strategy that must be implemented in the modernization construction, and the enhancing capacity for sustainable development is one of the goals of building a well-off society in all respects [19]. China's Five-Year Plan for economic and social development takes sustainable development as the core goal and arranges related tasks.

For the practices of sustainable development in China, the most representative is the construction of national sustainable development pilot zones. In 1986, China explored the construction of sustainable development pilot zone. After more than 30 years of development, the sustainable development pilot zone has become an important carrier of sustainable development concepts and policy [20]. Until 2014, China has established 189 national sustainable development pilot zones distributed in more than $90 \%$ of provinces, municipalities, and autonomous regions. In addition, in response to the 2030 Agenda for Sustainable Development, in 2016, China proposed to establish about 10 innovation demonstration zones by 2020 based on the work of the national sustainable development pilot zone. Until 2019, six innovation demonstration zones have been established [21]. This is a demonstration drive for solving the main contradictions of Chinese society in the new era and implementing the development tasks of the new era and provides experiences for the global sustainable development.

The existing researches on sustainable development pilot zones mainly include the following contents. (1) First is the construction of evaluation indicators for sustainable development pilot zones. Zhu et al. comprehensively used the analytic hierarchy process and expert consultation to construct a comprehensive evaluation index system corresponding to the SDGs [22]. Zhao et al. took Tongling city as an example and constructed a sustainable development indicator system based on the combination of material flow analysis and ecological footprint model [23]. Guo and Ding produced a comprehensive input and output indicator of data envelopment analysis (DEA) based on requirements of the DEA method [24]. (2) Second is the assessment of the development level of the sustainable development pilot zones. Li and Cao classified the sustainable development pilot zones into levels of high-coordination with strong-sustainability, low-coordination with weak-sustainability, and medium-type based on 14 prefecture-level cities in the country [25]. Niu put forward the equation of capacity for sustainable development construction [26]. In sum, the research of sustainable development pilot zone has undergone three stages of research start, expansion of connotation, and allround development. The research content involves many aspects, such as the theory and practice of pilot zone construction, development models, evaluation methods of the construction, implementation paths, and policy measures. In addition, the breadth and depth of theoretical and empirical research of sustainable development are slightly insufficient $[5,27,28]$. Some researchers have carried out multiscale, multilevel, and multifaceted series of research work on the construction of sustainable development pilot zones, and results are important for guiding the construction of pilot zones. However, the quantitative assessment of construction impact of sustainable development pilot zones is few. In addition, there are few researches about the relationship between socioeconomic development and environmental pollution in sustainable development pilot zones [29], as well as effects of the public awareness and level of economic development on the sustainable development pilot zones [30]. Most of the existing studies use the index requirements of the national sustainable development pilot zone to assess the construction impact. The existing assessment ideas or methods are insufficient to reflect the demonstration of the pilot zone construction. Therefore, the assessment methods should be changed to reflect not only the impact of the pilot zone construction but also the demonstration impact of the pilot zone construction. In 
this paper, 22 sustainable development pilot zones and 165 nonsustainable ones in prefecture-level cities were used as research samples, and panel data from 2006 to 2016 were adopted. Then, using propensity score matching and difference-in-difference (PSM-DID), the impact of the pilot zone construction on the environmental efficiency was discussed, including the impact effects and paths of the pilot zone constrution on environmental efficiency compared with the nonpilot zone. This can provide a reference for how to improve environmental efficiency in the construction of pilot zones and development process of other cities.

\section{Materials and Methods}

2.1. Evaluation Method of Environmental Efficiency. Environmental efficiency is the magnitude of the environmental impact caused by the unit economic value created by the social and economic system [31], as well as the measurement of environment cost of economic development, and one of standards to measure whether the economic development is sustainable [32]. If the environment is used as a factor to input, environmental efficiency requires obtaining the maximum economic output with the minimum environmental input (environmental pressure); namely, socioeconomic systems use environmental factor in the most efficient way [33]. This paper adopted the concept of environmental efficiency defined by the World Business Council for Sustainable Development (WBCSD): environmental efficiency (EE) is the measurement of the environmental impact of unit value created by a business, industry, or region:

$$
\mathrm{EE}=\frac{y}{\text { Environmental pressure }}
$$

where $y$ is the gross domestic product (GDP); environmental pressure in this paper is the amount of wastewater discharge, the amount of sulfur dioxide emissions, and the amount of soot emissions and unutilized industrial solid waste.

The traditional DEA method can classify the evaluation unit into only a valid unit or invalid unit. For the valid unit, the efficiency value is 1 . It is impossible to distinguish between good and bad ones [34]. Thus, a super-efficiency DEA model was used in this paper, which can make a comparison among relatively valid decision-making units. The basic idea is as follows. When a decision-making unit (DMU) is evaluated, as far as an invalid DMU is concerned, its production frontier remains unchanged, and thus the final efficiency value is equal to that measured with a traditional DEA model. When the valid DMU is evaluated, the reference set is formed by all other evaluation units, regardless of the unit being evaluated, and the result is valid. An effective DMU increases the input, and its efficiency may remain unchanged. Thus, for the efficient DMUs, the efficiency remains unchanged when the inputs of the DMUs are increased by a certain rate and the certain increased rate is the superefficiency scores [35]. The specific content of the superefficiency model was described in $[36,37]$.
2.2. Difference-in-Difference (DID) and Propensity Score Matching with Difference-in-Difference (PSM-DID). The DID is a method commonly used in policy evaluation. By this method, samples are divided into a processing group and a control group. The result of the control group is used as counterfactual result of the processing group, which is the result of the processing group without being impacted by the policy. Then, the policy effect can be obtained by calculating the difference in results between the processing group and control group [38]. The greatest advantage of the DID is that it can use the panel data to control the influence of unobservable variables, especially the influences of factors that are constant or synchronous over time [39]. However, because of different geographical locations and resource endowment, the development gap among cities is large, and there is a large heterogeneity. In addition, the time span of construction of the sustainable development pilot zone is long (e.g., as early as 1986, Changzhou has begun to construct the sustainable development pilot zone). It is difficult to meet the requirement of consistency between the time and effect. Thus, the propensity score matching (PSM) developed from Heckman (1976) and Rosenbaum and Rubin (1983) was used in this paper to eliminate the sample selection bias. However, PSM cannot avoid the endogenous problem caused by missing variables. DID can solve the endogenous problem and obtain the policy processing effect through difference in difference, but it cannot solve the problem of sample bias. Based on this, this paper adopted the method of PSM-DID [40] to more accurately assess the impact of sustainable development pilot zones on environmental efficiency.

According to the analysis, the regression model based on the DID method is as follows [40]:

$$
\mathrm{EE}(\mathrm{PP})_{i t}=a_{0}+a_{1} \mathrm{~d} u \times \mathrm{d} t+\sum_{i=1}^{N} b_{j} X_{\mathrm{it}}+\varepsilon_{\mathrm{it}} .
$$

The specific steps of robustness test based on the PSMDID method are (1) using the PSM to find the control group having characteristics closest to the experimental group and (2) using the matched experimental group and control group for DID regression. The model is as follows:

$$
\mathrm{EE}(\mathrm{PP})_{i t}^{\mathrm{PSM}}=a_{0}+a_{1} \mathrm{~d} u \times \mathrm{d} t+\sum_{i=1}^{N} b_{j} X_{\mathrm{it}}+\varepsilon_{\mathrm{it}},
$$

where $\mathrm{EE}(\mathrm{PP})$ is the environmental efficiency; $X$ is the control variable of the corresponding model and controlled variables that affect the environmental efficiency; $\mathrm{d} u$ is a dummy variable that decides whether the development of pilot zone is sustainable; $\mathrm{d} t$ is a dummy variable for time; subscripts $i$ and $t$ represent the $i^{\text {th }}$ City and the $t^{\text {th }}$ year, respectively; $\varepsilon$ is the disturbance term. Model (1) is an impact model of environmental efficiency and it is used to assess the impact of the construction of sustainable development pilot zone on environmental efficiency, in which the variables that affect environmental efficiency are environmental regulation index, the proportion of the output value of the secondary industry in the GDP, GDP per capita, and the output of 
science and technology. To ensure the uniformity, comparability, and scientificity of the analysis results, logarithmic processing was performed on all variable data.

2.3. Research Hypotheses. Based on the environmental Kuznets curve (EKC) hypothesis and the Porter hypothesis, we proposed the following hypotheses.

Hypothesis 1. (H1). The construction of a sustainable development pilot zone improves the environmental efficiency.

With the rise of the international environmental protection movement, the deterioration of the domestic ecological environment, and the lag of development of social undertakings, the country comprehensively solves the problems of environmental degradation, backward infrastructure, and social livelihood with the development of the economy based on the scientific and technological progress. Then, the construction of the national sustainable development pilot zone was proposed [5]. It aims to accumulate experience through the transformation of large cities, construction of small towns, community management, the environment protection, sustainable use of resources, development of resource-based cities, sustainable development and protection of tourism resources, and so forth [41] and provides demonstration for the sustainable development of other regions. This paper focuses on the environmental impact of the construction of sustainable development pilot zones. Therefore, the hypothesis that the construction of sustainable development pilot zones improves the environmental efficiency was proposed in this paper.

Hypothesis 2. (H2). The construction of sustainable development pilot zone improves the environmental efficiency by increasing the level of environmental regulation.

The Porter hypothesis proposes that enterprises can benefit from the environmental regulation, which stimulates the innovation and development of enterprises [42]. To reduce the amount of discharge of environmental pollutants and promote the sustainable development, the strategy of environmental regulation is implemented for enterprises inside the sustainable development pilot zone, which is one of the important methods to achieve the sustainable development goals. In the construction of the sustainable development pilot zone, the innovation activities of enterprises focus on two directions of improving productivity as well as environmental friendliness and reducing pollutant discharge. Therefore, the hypothesis that the construction of sustainable development pilot zone improves the environmental efficiency by increasing the level of environmental regulation was proposed in this paper.

Hypothesis 3. (H3). The construction of sustainable development pilot zone improves the environmental efficiency by reducing the proportion of industry.

Industrial structure, population size, and economic growth all have a certain inhibitory effect on the environmental improvement. Among them, the industrial structure has the strongest inhibitory effect on the improvement of environmental performance [35]. The construction of the sustainable development pilot zone is driven by the problems of uncoordinated social development and serious environmental pollution. The approval and construction of the sustainable development pilot zone promote the progress of science and technology, as well as the development of industrial transformation to reduce the proportion of industry. Improving environmental efficiency is one of the main goals. Based on this, we proposed the hypothesis that the construction of sustainable development pilot zone improves the environmental efficiency by reducing the proportion of industry.

Hypothesis 4. (H4). The construction of sustainable development pilot zone improves the environmental efficiency by increasing the technology level.

Many researchers reported that the improvement of technology has reduced China's industrial pollution [43]. Human capital and technological innovation significantly reduce the environmental pollution [44]. One of the main requirements for the application of the sustainable development pilot zone is that it has certain sustainable development capabilities, as well as the good economic, social, and technological foundations for promoting sustainable development. Therefore, science and technology are crucial for the construction of sustainable development pilot zone. The development of science and technology promotes the progress of production and environmental technologies, reduces the pollutant discharge, and improves the environmental efficiency. In addition, it promotes the development and use of new energy sources and reduces the environmental pollution caused by the fossil fuel combustion. Based on this, the hypothesis that the construction of sustainable development pilot zone improves the environmental efficiency by increasing the technology level was proposed in this paper.

Hypothesis 5. (H5). The construction of sustainable development pilot zone improves the environmental efficiency by increasing the level of economic development.

The EKC hypothesis indicates that the pollution level of a region first rises and then decreases with the economic development [45], which means that there is an inverted U-shaped relationship between the economic development and pollution level. Many studies have confirmed that EKC is ubiquitous [46]. Therefore, the environmental efficiency may decrease first and then increase with the increase of the level of economic development. The approval of sustainable development pilot zone brings the "policy bonus" and promotes the economic development of the region. When the economy develops to a certain extent, the level of pollution decreases, and the environmental efficiency will be improved. Based on this, the hypothesis that the construction of sustainable development pilot zone improves the environmental efficiency by increasing the level of economic development was proposed in this paper.

Among them, 1 is the impact-effect hypothesis, and 2-5 are the impact-mechanism hypotheses, which are used to 
analyze the specific impact path of the sustainable development pilot zone on the environmental efficiency.

2.4. Data. The data in this paper are from "China City Statistical Yearbook" of 2006-2016. The data of some prefecture-level cities are missing, and we used the average growth rate method to supplement them. The selected 187 prefecture-level cities include 22 national sustainable development pilot zones and 165 nonsustainable ones. According to the assessment standard of environmental efficiency and the availability of data, an assessment index system was established (Table 1). For the environmental efficiency assessment, the selection of DMU must meet two requirements [47]. One is that DMU should be of the same type. The other one is that the number of DMU is not less than twice the total number of input and output indicators. In this paper, 187 prefecture-level cities were selected as research samples. Therefore, they are comparable on the environmental efficiency, and the number is 37.4 times that of the index. This meets the selection requirements of DMU.

\section{Model Construction}

In this paper, we selected the national sustainable development pilot zones based on prefecture-level cities as research samples and used DID and PSM-DID methods to assess the impact of pilot zone construction on environmental efficiency. According to the research goals, we constructed two dummy variables. One is the dummy variable of experimental group and the control group. The experimental group is the national sustainable development pilot zone, and the value of it is defined as 1 . The control group is the nonsustainable one, and the value of it is defined as 0 . The other one is the dummy variable of policy-making time. That no later than 2011 is defined as 1, and that later than 2011 is defined as 0 . The national sustainable development pilot zone established before 2011 is defined as the experimental group, and the nonpilot city is defined as the control group. New national sustainable development pilot zones established after 2011 were used to test the robustness of the results.

Among the controlled variables, the industrial structure is expressed by the proportion of the secondary industry, the level of economic development is expressed by the GDP per capita, and the level of technological innovation and development of science and technology is expressed by the input of science and technology. Affected by the availability of data, the data of environmental treatment input for some years in China City Statistical Yearbook are missing. Therefore, an environmental regulation index was constructed, which is the weighted average value of the rate of sulfur dioxide reduction, the rate of industrial smoke and dust emissions, and the unutilized rate of general industrial solid wastes. This contains three aspects of air pollution treatment, industrial solid waste treatment, and environmental management in environmental treatment and is more comprehensive than environmental treatment input [48] (because the statistical data of wastewater treatment in
China City Statistical Yearbook before and after 2010 are inconsistent, the reduction rate of industrial wastewater discharge is removed).

\section{Results and Discussion}

4.1. Preliminary Assessment of the Impact of Sustainable Development Pilot Zone on Environmental Efficiency. In Table 2, model I is based on the whole 187 cities, regardless of the difference between sustainable and nonsustainable ones. To verify whether the EKC hypothesis is valid for the environmental efficiency, the environmental efficiency is used as the dependent variable, and the environmental regulation, industrial structure, the level of technology, economic development, and the square terms of economic growth are used as independent variables. Results show that the coefficient of the square term of GDP per capita is positive. This indicates that there is a $\mathrm{U}$-shaped relationship between the economic development and the environmental efficiency. The environmental efficiency first decreases and then increases with the increase of the level of economic development. Thus, the EKC hypothesis is valid for the environmental efficiency of the sample cities in this study.

Model II is the regression result without the control variable, and model III is the regression result with the control variable. Both models show the impact of construction of the sustainable development pilot zone on the environmental efficiency. Results show whether or not the control variable is included; the construction of sustainable development pilot zone has a positive impact on the environmental efficiency. When the control variable is not included, compared with that of nonpilot zone, the environment efficiency of the pilot zone increased by $27.4 \%$ (at a significance level of $10 \%)$. When the control variable is included, compared with that of nonpilot zone, the environment efficiency of the pilot zone increased by $27.7 \%$ (at a significance level of $10 \%$ ). This shows that the construction of sustainable development pilot zone can improve the environmental efficiency. Thus, Hypothesis 1 is valid.

The regression results of the control variable are as follows. When the 187 cities are considered as a whole without considering the differences between the pilot and nonpilot zones, control variables, including the environmental regulation index, scientific and technological input, and GDP per capita, all have positive impacts on the environmental efficiency (at a significant level of $1 \%$ ); at a significance level of $5 \%$, the proportion of the secondary industry has a positive impact on the environmental efficiency. The environmental regulation can effectively reduce pollutant emissions and then improve the environmental efficiency. In addition, the improvement of scientific and technological levels plays an important role in improvements of the technology, method, and equipment of production and pollution treatment. Then, it improves the productivity and environmental efficiency. 
TABLE 1: Assessment index system.

\begin{tabular}{lcc}
\hline Types & Index name & Index code \\
\hline & Wastewater discharge (10,000 tons) & (I)WW \\
Input & Industrial sulfur dioxide emissions (tons) & (I)SO $\mathrm{S}_{2}$ \\
& Industrial smoke and dust emissions (tons) & (I)SW \\
Output & Unutilized rate of general industrial solid wastes (\%) & (I)DUST \\
\hline
\end{tabular}

TABLE 2: The impact of the construction of sustainable development pilot zone on environmental efficiency.

\begin{tabular}{lccc}
\hline & & Environmental efficiency \\
& Model I & Model II & $0.274^{*}$ \\
DID & - & - & $0.277^{*}$ \\
Environmental regulation index & $0.272^{* * *}$ & - & $0.2451^{* * *}$ \\
Science and technology input & $0.096^{* * *}$ & - & $0.1043^{* * *}$ \\
Proportion of the secondary industry & $0.582^{* *}$ & - & $0.2669^{* *}$ \\
GDP per capita & $-5.047^{* * *}$ & - & $0.262^{* * *}$ \\
Quadratic GDP per capita & $0.252^{* * *}$ & - \\
\hline
\end{tabular}

Note: ${ }^{*},{ }^{* *}$, and ${ }^{* * *}$ represent significance levels of $10 \%, 5 \%$, and $1 \%$, respectively.

4.2. The Assessment Based on PSM-DID Method. To further verify the results of DID analysis, PSM-DID is used to assess the impact of the construction of national sustainable development pilot zone on environmental efficiency. First, the test of model suitability is performed. The results show that there is no significant difference between the experimental group and the control group. They are matched well. Therefore, this data is suitable for PSM. The impact of the sustainable development pilot zone on the environmental efficiency can be further assessed by PSM-DID.

The assessment based on PSM-DID is shown in Table 3. The construction of sustainable development pilot zone increases the environmental efficiency by $31.7 \%$ at a significance level of $1 \%$. There is no significant difference in results between PSM-DID and previous DID. This further verifies our conclusion that the construction of the national sustainable development pilot zone significantly improves the environmental efficiency.

Before the virtual implementation of the policy in 2011, the environmental efficiency of the sustainable development pilot zone is lower than that of the nonsustainable one. However, with the implementation of Eleventh Five-Year Plan, the environmental efficiency of the sustainable development pilot zone exceeds that of the nonsustainable one. In sum, the environmental efficiency of the sustainable development pilot zone increased by $31.7 \%$ at a significance level of $1 \%$.

4.3. Mechanism Test. In Table $4, \mathrm{~d} t$ is a time-controlled variable. The levels of environmental regulation, technology, and economic development in both the pilot and nonpilot zones are improved over time at a significance level of $1 \%$. The environmental regulation index increased by $12.02 \%$, science and technology input increased by $168.98 \%$, and GDP per capita increased by $72.25 \%$. The industrial structure remains unchanged over time, which means that the output of the secondary industry has not been significantly improved. The reasons are as follows. Firstly, there are differences in the foundation, focus, and path of development among cities, resulting in different industrial structures. Secondly, cities have a strong industrial agglomeration function. Besides the second industry, most of them are the third industry, especially the modern service industry.

$\mathrm{d} u$ is the control variable of "whether it is a sustainable development pilot zone." The model results show that, at the significance level of $1 \%$, the construction of the sustainable development pilot zone increases the proportion of the secondary industry output by $27.15 \%$ and the GDP per capita by $73.03 \%$. This indicates that the approval of the sustainable development pilot zone brings "policy dividends." It can improve the infrastructure and the development environment, adjust the industrial structure, and promote the economic growth.

Interactive item $g d$ is the key observation object of this paper. It can be used to measure the net impact of sustainable development pilot zone on each driving factor. The results show that the construction of sustainable development pilot zone improves the environmental regulation only at a significance level of $10 \%$ (compared with that of nonpilot zone, the environmental regulation level of pilot zone has increased by $7.37 \%$ ) and has a certain inhibitory impact on the industrial structure (compared with that of the nonpilot zone, the proportion of the secondary industry of the pilot zone has been reduced by $4.85 \%$ ) as well as no significant impact on the level of technology and economic growth. This indicates that Hypotheses 2 and 3 are valid and Hypotheses 4 and 5 are invalid. In addition, this result shows how the construction of China's sustainable development pilot zone improves the environmental efficiency; namely, the construction of the sustainable development pilot zone can improve the environmental efficiency by promoting the level of environmental regulation and reducing the proportion of the secondary industry. The impacts of technological level and economic development are not significant. In sum, the construction of sustainable development pilot zone has 
TABLE 3: The assessment based on PSM-DID method.

\begin{tabular}{lccc}
\hline & $\begin{array}{c}\text { Difference between experimental group and control } \\
\text { group before the implementation of policy }\end{array}$ & $\begin{array}{c}\text { Difference between experimental group and control } \\
\text { group after the implementation of policy }\end{array}$ & $\begin{array}{c}\text { DID } \\
\text { results }\end{array}$ \\
\hline $\begin{array}{l}\text { Difference } \\
\text { Standard }\end{array}$ & -0.225 & 0.092 & 0.317 \\
error & 0.070 & 0.079 & 0.105 \\
$T$ value & -3.23 & 1.17 & 3.02 \\
$P$ value & $0.001^{* * *}$ & 0.241 & $0.003^{* * *}$ \\
\hline
\end{tabular}

Note: ${ }^{* * *}$ represents a significance level of $1 \%$.

TABle 4: Mechanism test of sustainable development pilot zone.

\begin{tabular}{lcccc}
\hline & Inen & Ines & Inindustry & Inrgdp \\
\hline $\mathrm{d} t$ & $0.1202^{* * *}$ & $1.6898^{* * *}$ & 0.0155 & $0.7225^{* * *}$ \\
$\mathrm{~d} u$ & -0.0178 & 0.07172 & $0.2715^{* * *}$ & $0.7303^{* * *}$ \\
$g d$ & $0.0737^{*}$ & -0.0951 & $-0.0485^{*}$ & 0.0071 \\
\hline
\end{tabular}

shown an adverse impact on the improvement of environmental efficiency. However, the impact is not strong.

4.4. Further Test of the Robustness. In this paper, 2010 is set as the middle year of the policy pilot. To test the robustness of results, national sustainable development pilot zones established after 2011 are included to test whether the construction of sustainable development pilot zones can improve the environmental efficiency $[49,50]$. In this paper, the time span of construction of sustainable development pilot zones is long with a maximum value of 28 years. Thus, to identify whether the environmental efficiency of the sustainable development pilot zone varies with the sample time, the regression is performed by changing the middle year. If the regression results and significance are not significantly changed, the assessment results in this paper will be robust.

(1) The robustness of the policy effect is tested by including the new national sustainable development pilot zone established after 2011. Results show that the construction of sustainable development pilot zones improves the environmental efficiency.

(2) 2011 is set as the intermediate point. Samples in the ranges of 1 year, 2 years, and 3 years around the intermediate point are selected for regression. If the regression coefficient and significance are not significantly changed, the assessment results in this paper will be robust. The results show that, by changing the time interval of regression, sustainable development pilot zones all have positive impacts on the environmental efficiency coefficients. This proves that the conclusion of this paper is robust.

\section{Conclusions}

In this paper, 187 prefecture-level cities in China were taken as samples. Based on the theoretical framework of the EKC hypothesis and the Porter hypothesis, we analyzed the impact of the construction of the national sustainable development pilot zone on environmental efficiency, and the impact mechanism was tested using multivariate panel regression, DID model, and PSM-DID method. Results show that there is a U-shaped relationship between the economic development and environmental efficiency for the whole sample. This means that the environmental efficiency decreases first and then increases with the increase of the level of economic development. The construction of sustainable development pilot zone significantly improves the environmental efficiency. In sum, compared with that of the nonpilot zone, the environmental efficiency of the pilot zone can be increased by $27.7 \sim 31.7 \%$. The mechanism test shows that the environmental efficiency of sustainable development pilot zone is improved through environmental regulation and the adjustment of industrial structure. Compared with the industrial structure, environmental regulation has a more significant impact. In addition, the economic development and technological factors have not passed the mechanism test, which indicates that they do not play significant roles in improving the environmental efficiency.

The purpose of constructing China's sustainable development pilot zone is to explore mechanisms and models for coordinated economic, environmental, and social development in different types of zones and provide demonstrations for other regions. The basic goal of coordinated economic, environmental, and social development is to improve environmental efficiency. Therefore, the conclusions of this paper have significance for the improvement of environmental efficiency of sustainable development pilot zones and other cities. First, under current social and economic conditions, environmental regulation is the main mean to effectively improve the environmental efficiency. Second, the test of the impact mechanism of industrial structure shows that the decrease in the proportion of secondary industry in cities can improve the environmental efficiency, which indicates that the quality of the development of secondary industry needs to be further improved. Most cities in China are in the middle and late stages of industrialization. The industrial transformation and upgrading as well as structural optimization should be the key to China's industrial development. During the process of industrial upgrading and transformation, we must pay attention to the green transformation of the industry. Then, the coordinated development of economy and environment can be achieved. Third, the role of technological factors in the improvement of environmental efficiency has not yet been brought into play. The improvement of environmental efficiency depends on the two traditional methods of environmental regulation and the adjustment of industrial structure. Therefore, it is 
necessary to further tilt technology input towards energy saving, emission reduction, and green production, build a green production and supply chain, and further reduce pollutant emissions and resource consumption. Then, the innovation-driven green transformation and upgrading of industry are realized.

Due to the availability of data and the limitation of methods, this paper only studied the impact of the construction of the pilot zone on the overall environmental efficiency and did not analyze the effect of reducing the emissions of specific pollutants. In addition, the difference in environmental efficiency before and after the construction of the sustainable development pilot zone was analyzed. However, the time span of the construction of the sustainable development pilot zone is long, and China has made a series of policies to prevent the environmental degradation during this stage. These undoubtedly have impacts on the environmental efficiency. Thus, how to accurately analyze the impact of construction of sustainable development pilot zone on the environmental efficiency needs further discussion.

\section{Data Availability}

The data used to support the findings of this study are available from the corresponding author upon request.

\section{Conflicts of Interest}

The authors declare no conflicts of interest.

\section{Acknowledgments}

This work was financially supported by the National Key R\&D Program of China (Grant no. 2018YFC0704702), the National Natural Science Foundation of China (Grants nos. 41301652 and 41471116), and the Fundamental Research Funds for Central Universities (Grant no. lzujbky2018-137).

\section{References}

[1] X. Ru, X. Lu, and P. Li, Social Blue Book: Analysis and Forecast of China's Social Situation in 2012, China Society Press, Beijing, China, 2012.

[2] C. Fang, "The urbanization and urban development in China after the reform and opening up," Economic Geography, vol. 29, no. 1, pp. 19-25, 2009.

[3] S. Pulvirenti, P. Pavone, R. A. Carbonaro, and R. M. S. Costa, "Taxonomic study of the plants to be found in the onlyherbarium of Paolo Boccone (1633-1704) at present existing in Italy," Plant Biosystems-An International Journal Dealing with All Aspects of Plant Biology, vol. 151, no. 4, pp. 745-759, 2017.

[4] R. M. S. Costa and P. Pavone, "Diachronic biodiversity analysis of a metropolitan area in the Mediterranean region," Acta Horticulturae, vol. 1215, no. 1215, pp. 49-52, 2018.

[5] X. Sun, "Review and prospect of the construction of national sustainable development pilot zone," China Population, Resources and Environment, vol. 28, no. 1, pp. 10-15, 2018.
[6] S. Peng and X. Sun, "Global sustainable development report: background, progress and related suggestions," China Population, Resources and Environment, vol. 24, no. 12, pp. 1-5, 2015.

[7] B. Bayulken and D. Huisingh, "A literature review of historical trends and emerging theoretical approaches for developing sustainable cities (part 1)," Journal of Cleaner Production, vol. 109, no. 109, pp. 11-24, 2015.

[8] Y. Yang and Y. Liu, "Progress in China's sustainable development research: contribution of Chinese geographers," Journal of Geographical Sciences, vol. 26, no. 8, pp. 1176-1196, 2016.

[9] W. Colglazier, "Sustainable development agenda: 2030," Science, vol. 349, no. 6252, pp. 1048-1050, 2015.

[10] Y. Chu and Q. Soon, "Ecological footprint and regional sustainable development," Sustainable Development, vol. 9, no. 2, pp. 161-164, 2019.

[11] R. Steurer and G. Berger, “The EU's double-track pursuit of sustainable development in the 2000s: how Lisbon and sustainable development strategies ran past each other," International Journal of Sustainable Development \& World Ecology, vol. 18, no. 2, pp. 99-108, 2011.

[12] W. Clark and H. Lund, "Sustainable development in practice," Journal of Cleaner Production, vol. 15, no. 3, pp. 253-258, 2007.

[13] M. Pallemaerts and A. Azmanova, The European Union and Sustainable Development: Internal and External Dimensions, Vol. 24, VUB University Press, Brussels, Belgium, 2006.

[14] S. Sedlacek and V. Gaube, "Regions on their way to sustainability: the role of institutions in fostering sustainable development at the regional level," Environment, Development and Sustainability, vol. 12, no. 1, pp. 117-134, 2010.

[15] C. Sinkin, C. J. Wright, and R. D. Burnett, "Eco-efficiency and firm value," Journal of Accounting and Public Policy, vol. 27, no. 2, pp. 167-176, 2008.

[16] L. Tikly, "Education for sustainable development in Africa: a critique of regional agendas," Asia Pacific Education Review, vol. 20, no. 2, pp. 223-237, 2019.

[17] E. Kalipeni, J. Iwelunmor, and D. Grigsby-Toussaint, "Maternal and child health in Africa for sustainable development goals beyond 2015," Global Public Health, vol. 12, no. 6, pp. 643-647, 2017.

[18] Center CAM, "Management methods of national sustainable development pilot zone," 2007.

[19] Y. Tan, H. Xu, and X. Zhang, "Sustainable urbanization in China: a comprehensive literature review," Cities, vol. 55, no. 55, pp. 82-93, 2016.

[20] K. Jiang, "Resource and environmental performance evaluation of national sustainable development pilot zone in prefecture-level cities," Sustainable development, vol. 7, no. 2, pp. 102-109, 2017.

[21] X. Sun, “China's strategic thinking of establishing and implementing the 2030 sustainable development agenda innovation demonstration zone," China Population, Resources and Environment, vol. 27, no. 4, pp. 1-5, 2017.

[22] J. Zhu, X. Sun, and H. Zheng, "Research on evaluation indicators of China's sustainable development under SDGs," China population, Resources and Environment, vol. 28, no. 12, pp. 9-18, 2018.

[23] H. Zhao, X. Gu, Y. Wang, J. Zhou, and Y. Sun, "Construction of sustainable development index system based on material flow and ecological footprint: a case study of Tongling City, Anhui Province," Acta Ecologica Sinica, vol. 32, no. 7, pp. 2025-2032, 2012. 
[24] C. Guo and J. Ding, "Construction of DEA indicators for comprehensive evaluation of sustainable development," China Population, Resources and Environment, vol. 26, no. 3, pp. 9-17, 2016.

[25] J. Li and M. Cao, "Comparative study on the development level of national sustainable development pilot zones," Bulletin of Soil and Water Conservation, vol. 31, no. 6, pp. 160164, 2011.

[26] W. Niu, "Theory and practice of sustainable development in China," Proceedings of the Chinese Academy of Sciences, vol. 27, no. 3, pp. 280-289, 2012.

[27] J. Li, "Research status and prospects of national sustainable development pilot zones," Human Geography, vol. 26, no. 1, pp. 66-70, 2011.

[28] S. Liu, "Development status of the national sustainable development pilot zone in the central and South mountain area of shandong," Bulletin of Soil and Water Conservation, vol. 38, no. 3, pp. 312-317, 2018.

[29] M. Meng, T. T. Pang, and L. G. Fan, "Measuring and fitting the relationship between socioeconomic development and environmental pollution: a case of Beijing-Tianjin-Hebei region, China," Discrete Dynamics in Nature and Society, vol. 2019, Article ID 1570364, 10 pages, 2019.

[30] X. L. Yang, X. C. Dong, Q. Z. Jiang, and G. X. Liu, "Factors influencing public concern about environmental protection: an analysis from China," Discrete Dynamics in Nature and Society, vol. 2019, Article ID 5983160, 10 pages, 2019.

[31] Z. Zhang, X. Chen, and Y. Li, "Convergence of China's industrial environmental efficiency and its spatial differences," China Population, Resources and Environment, vol. 25, no. 2, pp. 30-38, 2015.

[32] K. Zhang, "Measurement and dynamic evolution of China's agricultural environmental efficiency from the perspective of strong disposability," China Population, Resources and Environment, vol. 26, no. 1, pp. 140-149, 2016.

[33] X. Yu, Empirical Study on Capacity Evaluation and Demonstration Effect of National Sustainable Development Pilot Zone, Southwest Jiaotong University, Chengdu, China, 2015.

[34] J. N. Wang, Z. Xu, X. Hu, X. Peng, and Y. Zhou, "Analysis of regional environmental efficiency in China based on DEA theory," China Environmental Science, vol. 30, no. 4, pp. 565-570, 2010.

[35] Z. Zhang, X. Chen, B. Xue, and C. Lu, "Analysis of China's urban environmental performance and its impact factors: analysis based on super-efficiency DEA model and panel regression," Journal of Arid Land Resources and Environment, vol. 29, no. 6, pp. 1-7, 2015.

[36] D. Yang, "Performance evaluation of logistics enterprises based on super-efficiency DEA-IAHP," Operations Research and Management, vol. 21, no. 1, pp. 189-194, 2012.

[37] H. Ma and H. Yao, "Research on total factor energy efficiency in three economic regions of China-based on super-efficiency DEA model and malmquist index," China Population, Resources and Environment, vol. 21, no. 11, pp. 38-43, 2011.

[38] Y.-J. Zhang, Y.-L. Peng, C.-Q. Ma, and B. Shen, "Can environmental innovation facilitate carbon emissions reduction? Evidence from China," Energy Policy, vol. 100, pp. 18-28, 2017.

[39] S. L. Haiyuan Wan, "The impact of household registration discrimination on the urban-rural income gap," Economic Research, vol. 48, no. 9, pp. 43-55, 2013.

[40] D. Shi, P. Wei, and J. Liu, "Can smart city construction reduce environmental pollution," China Industrial Economy, vol. 25, no. 6, pp. 117-135, 2018.
[41] N. Yao and X. Liu, "Status and effectiveness of the implementation of the national science and technology plan for sustainable development pilot zones," China Population, Resources and Environment, vol. 25, no. 1, pp. 158-161, 2015.

[42] S. Ambec and P. Barla, "A theoretical foundation of the Porter hypothesis," Economics Letters, vol. 75, no. 3, pp. 355-360, 2002.

[43] R. Liu, "Study on the trend and influencing factors of sulfur dioxide emissions in Chinese industry," Environmental Pollution and Control, vol. 34, no. 10, pp. 100-104, 2012.

[44] J. Lu and Y. Chen, "Impact mechanism of human capital and technological innovation on environmental pollution: an empirical analysis based on 285 cities across the country," Resources and Environment in the Yangtze, vol. 28, no. 9, pp. 2186-2196, 2019.

[45] S. Farhani, S. Mrizak, A. Chaibi, and C. Rault, "The environmental Kuznets curve and sustainability: a panel data analysis," Energy Policy, vol. 71, no. 71, pp. 189-198, 2014.

[46] X. Cui and Z. Fang, "Dynamic evolving inverted U-shaped environmental Kuznets curve," China Population, Resources and Environment, vol. 29, no. 9, pp. 74-82, 2019.

[47] D. Anderson, "Energy efficiency and the economists: the case for a policy based on economic principles," Annual Review of Energy \& the Environment, vol. 20, no. 1, pp. 495-511, 1995.

[48] N. Yang, Z. Zhang, B. Xue, J. Ma, X. Chen, and C. Lu, "Economic growth and pollution emission in China: structural path analysis," Sustainability, vol. 10, no. 7, p. 2569, 2018.

[49] Y. Dong, "Research on the employment effect of high-speed rail construction: evidence based on the PSM method of 285 cities in China," Economic Management, vol. 38, no. 11, pp. 26-44, 2016.

[50] A. Chalak, C. Abou-Daher, J. Chaaban, and M. G. Abiad, "The global economic and regulatory determinants of household food waste generation: a cross-country analysis," Waste Management, vol. 48, no. 48, pp. 418-422, 2016. 